returning to paid work was a function of prior level of mental ill health. Fourthly, other research in this unit shows that in areas of higher unemployment compared with those of lower unemployment unemployed people report feeling less stigmatised by the lack of a job, having more social contact with other unemployed people, and feeling less under pressure from other people to get a job.

Differential selection of unfit people in different areas is therefore unlikely to account for our findings.

PAul R Jackson

Department of Psychology,

ersity of Sheffield

Sheffield S10 2TN

\section{Fatal bronchospasm after topical lignocaine} before bronchoscopy

SIR,-I would like to suggest an alternative cause for the demise of the patient described by Drs S P Ruffles and J G Ayres (27 June, p 1658).

Though bronchospasm is, of course, a well recognised effect of an allergic reaction, sensitivity to lignocaine is exceedingly rare, a great deal rarer than pneumothorax in an emphysematous patient. It is well known in anaesthetic practice that any patient suspected of developing bronchospasm should have a pneumothorax excluded. The clinical signs, particularly with regard to wheezing, are very similar.

In the case described by Drs Ruffles and Ayres difficulty was encountered in ventilating the patient after cardiac arrest, indicating a physical impediment to the ventilation rather than a physiological one. It would be interesting to know if bronchospasm can persist for 20 minutes in the presence of a cardiac arrest. We are not told if necropsy was performed in such a way as to confirm or eliminate the presence of a tension pneumothorax, but if this was not suspected it was probably not.

The patient certainly developed a pneumothorax, and we are not told why the authors consider it unlikely to have been the initiating factor. Fractured ribs from the resuscitation should have been shown at necropsy. We are not told whether the bronchoscope had been inserted before the cardiac arrest or whether its insertion, or the insufflation of the lignocaine, was associated with a bout of coughing

While it is impossible to exclude a sensitivity reaction, it is also impossible to confirm it in this case in the absence of any immunological evidence of allergy, particularly when a pneumothorax that was discovered at necropsy cannot be eliminated as the primary cause of death.

D B ScotT

Edinburgh EH1 3EP

AUTHOR'S REPLY,-That the cause of death in our patient might have been a tension pneumothorax is possible, but, on balance, we believe that the lignocaine was more likely to have been responsible.

Ventilation of patients with severe asthma after a cardiorespiratory arrest is often very difficult even when an adequate cardiac output is maintained, and we believe that severe airway narrowing will persist in the presence of cardiorespiratory arrest during cardiopulmonary resuscitation. Though not mentioned in our report, fractured ribs were found at necropsy, and we had attributed the pneumothorax to these typical injuries after cardiopulmonary resuscitation. The episode of dyspnoea started two minutes after the lignocaine spray was administered, which is certainly too soon after delivery of the local anaesthetic to contem- plate passage of the bronchoscope, which had not been passed at the time of arrest. The patient did, however, cough a little after the lignocaine, something that is often seen. As far as the immunological evidence of allergy is concerned, it is difficult to know what Dr Scott would require for this at necropsy. In any case, we were careful to use the word sensitivity rather than allergy. We still believe that the most likely cause of this man's death was sensitivity to lignocaine, but, clearly, as with all single case reports, an open mind should be kept and I am sure that readers will draw their own conclusions.

East Birmingham Hospital, Birmingham B9 5ST

\section{Preventing insulin dependent diabetes} mellitus: the environmental challenge

SIR,-Diabetes Epidemiology Research International (22 August, p 479) emphasise the importance of environmental factors in the aetiology of insulin dependent diabetes with techniques developed for cancer epidemiology.

The possibility of an association between viral illness and insulin dependent diabetes has been entertained for many years. Epidemiologically, perhaps the most interesting recent development has been a series of reports, from both Europe $e^{1-4}$ and the United States, ${ }^{5}$ of a substantial secular increase in the incidence of insulin dependent diabetes in the past two decades. Assuming that these increases are real (and their consistency suggests that they may be), however, it seems necessary to identify an agent that has experienced important changes in its epidemiology in children during this time if viruses are to be held responsible and the agent or agents identified.

The greatest attention has been focused on the enteroviruses, ${ }^{6}$ but there is no strong evidence of such changes in members of this group. On the other hand, the epidemiology of some other common infections of childhood-measles, mumps, and rubella, in particular-has been profoundly influenced by immunisation programmes in Europe and North America during the past 20 years. Both mumps and rubella have also been implicated in the aetiology of insulin dependent diabetes, although the evidence remains circumstantial. ${ }^{67}$ There is also the possibility that widespread immunisation has, coincidentally, changed the epidemiology of other, as yet unidentified or unsuspected, infectious agents.

In considering a mechanism whereby a reduction in the incidence of a disease, through immunisation, might result in an increase in the total incidence of a morbid outcome, it must be remembered that there is often an upwards shift in the average age of onset of infectious diseases in populations in which immunisation has been widespread but incomplete. It is feasible in such circumstances that infection at a later age may carry an increased risk of subsequent $B$ cell destruction, sufficient to result in a net increase in the incidence of insulin dependent diabetes. Given the rarity of the disease in most populations, a modest increase in the absolute number of cases might represent a substantial increase in incidence.

The concept of an age related increase in the frequency of pancreatic complications is also congruent with the early ubiquity of viral infections and the unexplained rarity of insulin dependent diabetes in many developing countries in the tropics. Seen in this way, the occurrence of insulin dependent diabetes in developed societies might be considered to be the result of evolutionarily "unnatural" developments in public health. Low expressivity under traditional cir- cumstances would also help to explain how the genotype predisposing to such a formerly fatal condition might have persisted with such frequency.

Furthermore, this reasoning suggests an intriguing link between the aetiology of insulin dependent and non-insulin dependent diabetes. Though the two forms of the disease differ fundamentally in their underlying pathology and mechanisms, ${ }^{8}$ the apparent increase in the incidence of insulin dependent diabetes in white populations has a parallel in the epidemic of noninsulin dependent diabetes that has occurred in this century in certain indigenous societies in North America and the western Pacific as a result of factors which, though probably unrelated, are also believed to be closely associated with sociocultural change. ${ }^{910}$

From this we might conclude that, to a large extent, both forms of diabetes are adverse consequences of fairly recent changes in human ecology.

HilARY KING

Division of Noncommunicable Diseases,

World Health Organisation,

CH-1211 Geneva 27, Switzerland

Patterson CC, Thorogood M, Smith PG, Heasman MA, Clarke JA, Mann JI. Epidemiology of type 1 (insulin dependent)
diabetes in Scotland 1968-1976: evidence of an increasing diabetes in Scotland 1968-1976: evide
incidence. Diabetologia 1983;24:238-43.

2 Joner G, Søvik $O$. Incidence, age at onset and seasonal variation of diabetes mellitus in Norwegian children, 1973-1977. Acto Paediatr Scand 1977;70:329-35.

3 Reunanen A, Åkerblom H, Käär M-L. Prevalence and ten year (1970-1979) incidence of insulin dependent diabetes mellitus in children and adolescents in Finland. Acta Paediatr Scand 1982;71:893-9.

4 Rewers M, LaPorte RE, Walczak M, Dmochowski K, Bogaczynska E. Apparent epidemic of insulin-dependent diabetes mellitus in Midwestern Poland. Diabetes 1987;36:106-13.

5 North AF, Gorwitz K, Sultz HA. A secular increase in the incidence of juvenile diabetes mellitus. $\mathcal{f}$ Paediatr 1977;91 706-10.

6 Barrett-Connor $\mathrm{E}$. Is insulin dependent diabetes mellitus caused by Coxsackievirus B infection? A review of the epidemiological evidence. Rev Infect Dis 1985; 7:207-15.

7 Gamble DR. The epidemiology of insulin dependent diabetes, with particular reference to the relationship of virus infection to its aetiology. Epidemiol Rev 1980;2:49-70.

8 World Health Organisation. Diabetes mellitus: report of a WHO study group. Geneva: World Health Organisation, 1985. study group. Geneva: World

9 Knowler WC, Bennett WC, Hamman RF, Miller M. Diabetes incidence and prevalence in the Pima Indians: a 19 fold greater incidence than in Rochester, Minnesota. Am $\mathcal{f}$ Epidemiol 1978;108:497-504.

10 Zimmet P, King H, Taylor R, et al. The high prevalence of diabetes mellitus, impaired glucose tolerance and diabetic retinopathy in Nauru-the 1982 survey. Diabetes Research 1984;1:13-8.

\section{Keeping up with orthopaedic epidemic}

SIR,-Mr Christopher Bulstrode's statement (29 August, p 514) is timely indeed. At a time when every effort is being made to "melt" the treatment of the arthritic hip by the total arthroplasty method into the routine running of the district general hospital few appreciate the problems entailed.

Total hip arthroplasty spells the beginning of treatment for a patient and must not be compared with soft tissue surgery. In our training, and in an attempt to satisfy the system providing the care, no allowance is made for the need to study the long term results of this or any other procedure.

The logistics of continuous follow up of patients with total hip replacements are still not fully appreciated. Patients and surgeons must realise that revision surgery will at times have to be carried out on the basis of radiographic changes alone; failure to do this results in progressive loss of bone stock, which makes revision surgery increasingly difficult, expensive, and of poor quality. Testing of components is essential, and the British Standards Institute is well aware of measures derived from clinical experience, but surgical technique can only be tested by assessing the long term results. In 